Universidad de Guadalajara

DERECHO GLOBAL. ESTUDIOS SOBRE DERECHO Y JUSTICIA

Año 2021, Vol. VI. Número 18, Julio-Octubre, ISSN: 2448-5128 e-ISSN: 2448-5136 https://DOI.org/10.32870/dgedj.v6i18.341

\title{
EL JUICIO de AMPARo COMO PIEDRA DE TOQUE DE LA CULTURA DE LA LEGALIDAD
}

\section{THE AMPARO JUDGMENT AS A TOUCHSTONE OF THE CULTURE OF LEGALITY}

Cómo citar el artículo:

Quitano D, (2021). El Juicio de Amparo como Piedra de Toque de la Cultura de la Legalidad. Derecho Global, Estudios sobre Derecho y Justicia, VI (18) https://DOI.org/10.32870 /dgedj.v6i18.341 pp. 43-77

Recibido: 11/03/2020 Aceptado: 09/09/2020 


\title{
RESUMEN
}

El presente trabajo desarrolla una reflexión acerca del carácter interdisciplinario del concepto "cultura de la legalidad" cuando se convierte en objeto de investigación en el campo de las ciencias sociales, y principalmente en la disciplina del derecho. Para argumentar esta postura, en primer término, es insoslayable precisar su relación con el Juicio de Amparo, uno de los instrumentos más importantes para la vigencia del Estado de Derecho, representada en la Constitución como norma suprema, la justicia constitucional, los procesos constitucionales, el control de constitucionalidad de las leyes, y la protección de los Derechos Fundamentales. Toda vez que el 6 y 10 de junio de 2011, se publicaron dos importantes reformas a la Constitución Política de los Estados Unidos Mexicanos que impactan directamente en la administración de justicia federal en aras de mejorar las condiciones y la vigencia del Estado de Derecho en México.

\section{Palabras Claves}

Legalidad, Justicia Constitucional, Estado de Derecho

\begin{abstract}
The present work develops a reflection on the interdisciplinary character of the concept "culture of legality" when it becomes an object of research in the field of social sciences, and mainly in the discipline of law. To argue this position, in the first place, it is unavoidable to clarify its relationship with the Amparo Trial, one of the most important instruments for the rule of law, represented in the Constitution as the supreme norm, constitutional justice, constitutional processes, the control of constitutionality of laws, and the protection of Fundamental Rights. Since on June 6 and 10, 2011, two important reforms to the Political Constitution of the United Mexican States were published that directly impact the administration of federal justice in order to improve the conditions and validity of the Rule of Law in Mexico.
\end{abstract}

\section{KEY WORDS}

Legality, Constitutional Justice, Rule of Law 
Sumario: I. Introducción. II. Justicia Constitucional. III. Estado de Derecho. IV. Principio de Legalidad. V. Relevancia del Juicio de Amparo. VI. Conclusiones. Bibliografía

\section{INTRODUCCIÓN}

El 6 de junio 2011, se publicó una importante reforma a la Constitución Política de los Estados Unidos Mexicanos concerniente al Juicio de Amparo, institución protectora de los derechos fundamentales por antonomasia, el cual se ve robustecido al ampliarse la procedencia del amparo respecto de cualquier norma general, al preverse su procedencia por violaciones a los derechos humanos plasmados en los tratados internacionales de los que el Estado mexicano sea parte.

Senda reforma acudió e impactó positivamente en el criterio garantista reactivo, con la introducción de figuras como el amparo adhesivo y los intereses legítimos, individual y colectivo; la adopción de nuevos conceptos en torno a la violación de derechos por omisión de las autoridades; la declaratoria general de inconstitucionalidad cuyos alcances y condiciones se determinarán en la ley reglamentaria; la creación de los Plenos de Circuito; y una nueva forma de integrar jurisprudencia "por sustitución".

Días después el 10 de junio del mismo año, con íntima relación con la anterior, se evidencia el reconocimiento de la progresividad de los derechos humanos, mediante la expresión clara del principio pro persona como rector de la interpretación y aplicación de las normas jurídicas, en aquellas que favorezcan y brinden mayor protección a las personas.

Así, la ampliación de los derechos que significa la concreción de algunas cláusulas constitucionales, como aquella relativa a los migrantes o a la suspensión de garantías, aunada a la obligación expresa de observar los tratados internacionales firmados por el Estado mexicano, miran hacia la justiciabilidad y eficacia de los 
derechos que, a la postre, se expande al mejoramiento de las condiciones de vida de la sociedad y al desarrollo de cada persona en lo individual. ${ }^{1}$

Las reformas constitucionales antes referidas generan la impostergable necesidad de profundizar en el estudio de los tratados internacionales en los que se reconocen derechos humanos y en que el Estado mexicano es parte; por lo cual se ha estimado indispensable hacer del conocimiento público un listado enunciativo, no limitativo, de los instrumentos internacionales de esa naturaleza, clasificados por la materia en que inciden.

A lo cual, independientemente de esa fuerza retardataria y la alineación de la conciencia jurídica se ve marcada en la eficacia de la norma, que es el factor que da vigencia al derecho. Hacer una norma legal que sirva para lo que se quiere que sirva exige competencia para crearla, para certificar su validez. Por ello, consideramos que una norma mal elaborada provoca su propia invalidez e ineficacia. Lo que debía ser una solución termina siendo causa de nuevos males. Dicha corrección no solo tiene un cauce legislativo, sino también social, fincado en la cultura de la legalidad.

Condición que se presenta débil de conformidad a las estadísticas y numeraria vigente como consecuencia de estudios serios en la materia. Como evidencia empírica, México es el segundo país con más impunidad en el mundo, posicionado en el escalón 59 entre los países más impunes, sólo detrás de Filipinas, según el Índice Global de Impunidad, elaborado por la Universidad de las Américas Puebla (UDLAP) y Consejo Ciudadano de Seguridad y Justicia de Puebla (CCSJ).

El Sistema de Justicia Mexicano, según el estudio, enfrenta grandes deficiencias: $46 \%$ de la población detenida carece de una sentencia condenatoria. El índice estimó una proporción promedio internacional de 17 jueces por cada 100,000

\footnotetext{
${ }^{1}$ Reformas Constitucionales en materia de Amparo y Derechos Humanos publicadas en junio de 2011 (Relación de tratados internacionales de los que el Estado Mexicano es parte en los que se reconocen Derechos Humanos) http://www.internet2.scjn.gob.mx/red/constitucion (Consultado el día 28 de enero de 2020)
} 
El Juicio de amparo como piedra de toque de la Cultura de la Legalidad

habitantes; México sólo cuenta con 4 por cada 100,000. La corrupción, la inseguridad y violencia al interior de los países son los efectos de la impunidad, no sus causas.

Conforme a lo establecido anteriormente se exhibe que la sociedad cuenta con escepticismo ante las instituciones alejándose del esquema probatorio, mismo que es elemento esencial en la estructuración del Estado de Derecho, lo que nos posiciona ante el Juicio de Amparo, como el último recurso que sirve como sostén respecto a la credibilidad legal y funcionamiento del mismo aparato estamental.

\section{La Justicia Constitucional}

Para mantener el Estado Constitucional de Derecho existen diversas Garantías Constitucionales, como puede ser el control de Constitucionalidad, mismo que es un proceso específico para evitar la existencia de leyes inconstitucionales, es decir, para corroborar la existencia de contradicciones entre las leyes y la Constitución y es sólo una de las tareas de la justicia constitucional. Este concepto tiene que ver con la aplicación de la Constitución, la garantía de esta y su eficacia normativa. Pues al considerarse la Constitución como una norma, es necesario garantizar su aplicación para que goce de eficacia.

Lo anterior debido a que si bien en una definición única y clase de justicia constitucional, sí existe un acuerdo general de qué procesos la constituyen. En este sentido, Hernández Abascal (2017) nos menciona, que entendemos la justicia constitucional como todos aquellos procesos constitucionales que tienen como fin garantizar la aplicación de la constitución, considerando ésta como norma jurídica suprema.

En cuanto a la pregunta de hasta dónde, es ya clásico el libro "Democracia y desconfianza" de John Hart Ely, donde se debaten los alcances de la facultad del juez al interpretar la Constitución, planteando la dicotomía entre el textualismo y la interpretación libre. Ésta problemática se posiciona abierta pues es obvio 
que cuando el órgano jurisdiccional constitucional, ya sea de control difuso o concentrado decide una cuestión de su competencia forzosamente hace algún tipo de interpretación de los preceptos constitucionales en cuestión.

La situación que reviste en un mundo tan diverso donde las necesidades sociales avanzan geométricamente y las leyes aritméticamente. Es de capital interés, reflexionar que para fortalecer la validez de la norma constitucional, debemos partir de la reflexión preexistente en el hecho de que si aplicar la expresión tácita o interpretación libre, dicha deliberación se halla en la punta del garantismo, en México se encuentra reflejado en el último juicio de la búsqueda de la administración de justicia, expuesto en el juicio de amparo.

Mismo que debe ser el último recurso, cuando el proceso y/o procedimiento no encuentra vicios ni alteraciones a las posibles sentencias enarboladas en los derechos humanos y sus garantías.

Para ello, es preciso edificar el análisis de la norma, y conceptualizarlo en una discusión donde se enfatiza la necesidad de mantener una relación constante entre la construcción teórica y la investigación empírica, valiéndome de los principios epistemológicos que al respecto desarrollaron autores como Jonh Locke, Max Weber, Friedrich Hayek, John Rawls, Gustavo Zagrebelsky y HéctorFix-Zamudio, entre otros.

A fin de no darle una lectura hermética del derecho, ya que se considera necesario abordar el estudio de la cultura de la legalidad desde una perspectiva ecléctica al interior del campo de las ciencias sociales, lo que nos permita conocer de mejor manera las variables que son determinantes en el desenvolvimiento de los actores en su relación con las leyes, así como la manera en que estos edifican esa legalidad a partir de la construcción de su propia subjetividad. En relación con el tema de validez de las normas, García Máynez (1960) concluía que el derecho formalmente válido es el conjunto de reglas bilaterales de conducta que el poder público considera obligatorias en un determinado país y en una cierta 
época. La corriente iusnaturalista vincula el concepto de validez del derecho con la obligatoriedad moral; así, una norma es solamente válida cuando se ajusta a valores morales. En ese sentido, Rodolfo Vázquez señala que, de acuerdo con esta concepción: "existe compatibilidad entre el deber prescrito en la norma y la concepción del deber, como categoría moral” ( Vazquez: 1976)

De esta manera tenemos que el concepto de validez es tratado desde dos perspectivas, la positiva, apegada al criterio formal de emisión de normas - un órgano creador competente que sigue el procedimiento establecido - y la iusnaturalista, como norma apegada a valores morales establecidos.

Por otro lado, existen perspectivas más nutridas, las cuales radican en la idea de la validez, en donde la norma tiene otro elemento, la eficacia. Es eficaz una norma que se cumple. Los individuos deben obedecer u observar las normas jurídicas válidas. Sin embargo, se trata de un deber dirigido a personas libres, lo que significa, que éstas pueden obedecer o no las normas jurídicas, a pesar de que conozcan cuáles son las consecuencias jurídicas de su obediencia.

Para lo que es preciso revisar, si en términos generales es la eficacia de la norma la que puede medir cualitativamente, la cultura de la legalidad, esta vinculación estaría en estrecha relación con los niveles de impunidad, al tiempo de atender lo escrito por Weber respecto a la legitimidad del conceptos socialmente aceptado por la sociedad al entender la importancia de la corrección burocrática de la utilidad del marco normativo, y ni si diga, de la ejemplificación expuesta en el Ensayo sobre la Tolerancia de John Locke, tratar rol que juega el individuo al momento de aceptar o no el cumplimiento de una ley. Convencionalmente, en la teoría del derecho se afirma constantemente que si una norma jurídica (el núcleo de la norma) se cumple sin excepción, entonces el deber ser se transforma en ser, en una coincidencia de validez con efectividad que los sociólogos denominan: normalidad (García de la Cruz: 2006) 
Dicho hilo conductor expone que la noción de seguridad jurídica está estrechamente relacionada con cultura de la legalidad. La lógica es relativamente sencilla: solo estoy seguro en un contexto en el que puedo prever con certeza las consecuencias de mis acciones. Y este elemento es fundamental para muchos ámbitos de nuestras vidas. Esto es así porque sólo nos atreveremos a emprender determinadas decisiones o a realizar ciertos actos si contamos con la seguridad de que las consecuencias previstas por las normas surtirán efectos. Cabe recordar que el Estado moderno surgió como un Estado jurídico; esto es, como un Estado Constitucional de Derecho.

Sin embargo, el tipo moderno de democracia constitucional afirma que "el poder es del pueblo" y se establece una concepción sobre las fuentes y sobre la legitimidad del poder. Para este efecto, democracia el poder es legítimo solo cuando su investidura viene de abajo, solo si emana de la voluntad popular, lo cual significa, en concreto, si es, y en cuanto libremente consentido, (Sartori: 2003).

A diferencia de los Estados totalitarios, que fundan su legitimidad (en Weber no cabría) en el reconocimiento de la igual digna de todas las personas y cuenta con instituciones diseñadas con la finalidad específica de garantizarla. Así es como Locke desarrolla su concepto de libertad, entendido como el derecho de los hombres para conducirse y disponer de sus bienes como les convenga, respetando los límites que establece la ley natural, sin depender de la voluntad de otra persona", el orden quedaría subordinado a este valor supremo (Weber: 838).

Se afirma que Locke es un pilar fundamental dentro de la ideología llamada liberalismo, ya que en su "Ensayo sobre el gobierno civil", exalta los derechos individuales, como eje importante en la vida del ser humano en la sociedad. El hombre en naturaleza posee un conjunto de derechos individuales, de carácter irrenunciable. El liberalismo de Locke otorga gran importancia a la individualidad de los habitantes de una comunidad para así poder establecer serios límites al poder. (p. 45) 
Estado y Derecho, (Márquez Rábago) son un binomio necesario para el buen funcionamiento de cualquier sociedad; el Estado necesita la legitimidad que el Derecho le brinda, para encuadrar su actuación y limitar la acción del gobernado, el Derecho es la fuerza coercitiva del Estado, que reprime las desviaciones, los incumplimientos y resuelve las controversias que se presenten dentro del amplio Pacto Social, materialmente lo vemos plasmado en la justicia constitucional, en sus diversas acepciones.

\section{Estado De Derecho}

El concepto Estado de Derecho es manejado de diversa forma por los doctrinarios y los políticos; mientras que para los segundos se usa para pedir, cuando así conviene a sus intereses, el apego a la ley, la opinión de los primeros difiere en alguna medida entre ellos, por los elementos indispensables para reconocer en una sociedad el transcurso de su vida en un Estado de Derecho.

Para Jaime Cárdenas Gracia, es el marco que permite el equilibrio entre las nociones Estado -aparato y Estado - comunidad, es el diseño institucional, y este equilibrio no puede descansar más que en la construcción de un Estado de Derecho.

Nos surge otra interrogante: ¿Cuándo puede decirse que hay un Estado de derecho? Para lo que se puede enmarcar típicamente que deben cumplirse varias características:

Primera: Que, cuando la materialidad del conjunto legal sea tenida como leitmotiv ${ }^{2}$ del sistema normativo y de las acciones que de él se derivan: ya que el concepto Estado de derecho puede llenarse con distintos contenidos, debe saberse cuál es el determinante de cada orden concreto.

\footnotetext{
${ }^{2}$ Palabra, expresión, verso, figura retórica (imagen, metáfora, etc.) o idea que se repite a intervalos a lo largo de una obra, generalmente con distinta forma.
} 
Segunda: Condición es que haya coherencia entre el paradigma que se ha impuesto o se quiere imponer y la formulación de las normas jurídicas.

Tercera: Debe haber calidad técnica en la formulación de las normas dentro de las formas jurídicas vigentes.

Cuarta: Para que exista un Estado de derecho los titulares de los órganos del Estado deben saber operar en el orden jurídico, sin violar sus reglas, para cumplir con las tareas que imponen las normas más allá de lo estrictamente formal.

Todo Estado de derecho debe tener las siguientes características:

a) Contar con un ordenamiento jurídico encabezado por algún documento constitucional

b) Reconocer un catálogo de derechos básicos de las personas

c) Establecer el principio de separación de poderes como un mecanismo para limitar al poder (y, esta forma, impedir cualquier forma de autoritarismo)

d) Establecer mandatos- leyes, normas- generales y abstractas para asegurar igualdad y certeza jurídica a las personas.Garantizar que esas normas sean prospectivas. Es decir que, una vez que han sido aprobadas surtan efectos hacia el futuro y no hacia el pasado para ofrecer seguridad jurídica de las personas. A este postulado se le conoce como el principio de "retroactividad de las leyes"3.

e) Garantizar que esas normas sean estables en el tiempo (las normas están cambiando constantemente las personas no pueden programar con certeza sus acciones ni prever las consecuencias de estas)

f) Las normas deben ser públicas y accesible para las personas

g) Deben existir jueces o tribunales imparciales encargados de vigilar y garantizar el cumplimiento de las normas (tanto por parte de los poderes del Estado como de los individuos en general)

\footnotetext{
${ }^{3}$ Para el caso de la Constitución Mexicana, éste se encuentra recogido dentro de los artículos 14 y 16.
} 
Cabe destacar que las anteriores características solo son tipos ideales, es el ejercicio diario lo que podría alcanzar su materialización, como muestra Índice de Estado de derecho 2019 de World Justice Project (WJP), por segundo año consecutivo más países empeoraron de los que mejoraron. Por su parte, México descendió dos lugares respecto a la pasada edición del estudio.

Toda vez que el Estado de derecho es la base para que las comunidades gocen de paz, igualdad y oportunidades. Si bien ningún país ha alcanzado un Estado de derecho perfecto, el índice del WJP es un primer paso para establecer puntos de referencia, informar y enfatizar su importancia.

A pesar de mantener la misma calificación de 0.45 (en una escala entre el 0 y 1 ), México descendió dos lugares con respecto a la edición pasada del índice, lo cual lo coloca en el puesto 99 de 126 países. A nivel regional, México se ubica en el puesto 26 de 30 países, mientras que, de acuerdo con la comparación por nivel de ingreso, nuestro país se coloca en el lugar 35 de 38.

Por factor, las calificaciones para nuestro país son:

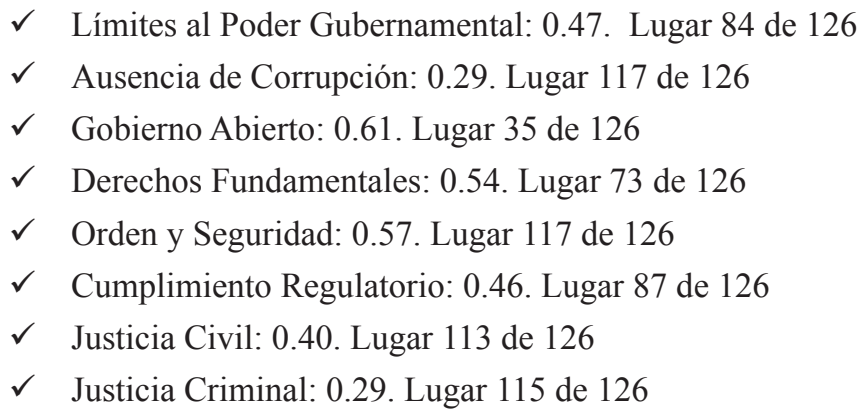

Pero esto no es porque la gente sea mala o por "cultura" sino que es una consecuencia de arraigo, ya se argumentaba que un hombre de bien solo puede ser un buen ciudadano en el seno de una ciudad buena, ${ }^{6}$ excepto que Kant concluye (y esto resulta 
muy sorprendente y va más allá de Aristóteles a la hora de separar la moralidad y buena ciudadanía). ${ }^{4}$

Así que más allá de dichas reflexiones el establecimiento del Estado de derecho en una sociedad anónima, desigual y lastimada como la mexicana, no es simple ni rápido. Sobre todo, cuando las prácticas públicas y privadas que las financian y recrean propician las condiciones existentes. La desesperanza y la magnitud del desorden han producido malos diagnósticos.

El autor Alejandro Correa Ortiz ${ }^{5}$ que sostiene que México es un país de leyes en la forma, pero con enormes niveles de impunidad e ineficacia para aplicarlas o, peor aún, para entenderlas. El cumplimiento es difícil y depende del grado o nivel de conveniencia social; por tanto, el hecho de que existan más de 3,000 leyes, reglamentos y bandos de gobierno a nivel federal, estatal, municipal y de alcaldías, no incentiva o disuade a la población a respetarlas o violentarlas; así, se antoja quimérico que la sociedad mexicana pueda dar cuenta del viejo aforismo: "La ignorancia de la ley no exime de su cumplimiento".

Derivado de ese argumento, surge la pregunta expresa sobre ¿por qué respeta y obedece las leyes? "Los Mexicanos y su Constitución. Tercera Encuesta Nacional de Cultura Constitucional (Héctor Fix Fierro y Flores, et al). Sólo un 38\% de la población mexicana considera que las respeta porque nos benefician a todos; en contraste, un estimado de $37.2 \%$ sostiene que lo hace para no ser criticado por los demás, para evitar daños a su familia y amistades o, bien, para evitar castigos. Un $22.9 \%$ adujo que cumplía las leyes porque es un deber moral; este último porcentaje agrega un componente subjetivo, pues es probable que muchos

\footnotetext{
${ }^{4}$ Cope, E. M.: Comentarios sobre la "Retórica" de Aristóteles (Commentary on the Rhetoric of Aristotle) (Recuperado el 5 de abril de 2020) http://www.perseus.tufts.edu/hopper/text?doc=Perseus\%3atext\% 3a1999.04.0080

${ }^{5}$ En su obra, Cultura de la Legalidad y Derechos Humanos" editada por la Comisión Nacional de los Derechos Humanos, (CNDH)
} 
ciudadanos sólo cumplan las reglas si lo consideran bueno en su fuero interno y, por tanto, en caso contrario, se justificaría su incumplimiento (p. 25).

Por otro lado, Kant (2019) en Observaciones acerca del sentimiento de lo bello y lo sublime, argumenta que los hombres que obran según principios son muy pocos, cosa que hasta es muy conveniente, pues con facilidad estos principios resultan equivocados. Los que obedecen a bondad espontánea son muchos más (que los que actúan con base en principios). Sin embargo, estos instintos virtuosos, cumplen perfectamente el gran propósito de la naturaleza, lo mismo que los demás instintitos, merced a los cuales se mueve con tanta regularidad en el mundo animal, dar ese salto experimental, aunque pueda parecer un tratamiento epistemológico, es esencial para mejorar el andar del derecho, toda vez que el derecho primero es una construcción psicosocial.

A fin de que Estado de Derecho y lo normativo en lo particular alcancen sus fines es necesaria la conformidad y respeto que los gobernados y gobernantes le tengan. Éstos son temas de incumbencia general para todas las disciplinas de las ciencias sociales, sin excepción alguna, donde el cooperativismo integral es indispensable para optimar el desarrollo de la sociedad en su conjunto.

Hasta llegar a un punto, en el cual una persona no inflija la ley, aunque perciba que es injusta. Si eso ocurriera, estaría dispuesta a utilizar los mecanismos legales (procesos legislativos, o iniciativas ciudadanas) para intentar cambiar la ley. La población puede recurrir a la desobediencia civil para resolver leyes percibidas como injustas y estarían dispuestos a aceptar las consecuencias de sus acciones. La cultura de legalidad es un ideal difícil de alcanzar, al igual que el Estado de Derecho pero que vale la pena aspirar a lograrlo, a través de su análisis y construcción de las dimensiones mismas.

El Estado de derecho requiere, ciertos niveles de cumplimiento espontaneo de las leyes por parte de los sujetos públicos y privados sometidos a ellas. Es indispensable 
también, porque cuando las normas jurídicas no se cumplan, se persiga y sancione a los responsables de la desviación. Hacer una norma legal que sirva para lo que se quiere que sirva exige competencia para crearla, para certificar su validez. Una norma mal elaborada provoca su propia invalidez e ineficacia. Lo que debía ser una solución termina siendo causa de nuevos males. Enfrentamos un resquebrajamiento y un desdibujamiento de las fronteras entre lo legal y lo ilegal.

Como veremos más adelante, las reglas se crean para evitar la incertidumbre y combatir el caos, superar el desorden y conjurar la destrucción; se hacen valer con razones y argumentos; se sostienen con el ejemplo de los primeros obligados a observarlas: los gobernantes; se reproducen cuando los habitantes de la nación aprenden a amarlas porque les brindan el beneficio de la seguridad y la protección para sus vidas; se garantizan, en última instancia, con la fuerza coercitiva del Estado, también sujeta, por cierto a la propia legalidad.

\section{Principio de Legalidad}

Repensar conceptos como legalidad, en la disciplina jurídica es esencial, sin embargo, los contextos son la fuente que marca el tamiz bajo el cual se ha de emitir una opinión. La procuración de justicia históricamente ha de ser la fuente bajo la cual se sustenta el derecho, dicha concepción coercitiva es lo que le da vigencia y plenitud a la norma.

La cultura de la legalidad y la primacía del Estado de derecho son los temas ausentes en las discusiones y coyunturas políticas, pero ya son de trascendencia intergeneracional e inevitables; si los mexicanos no somos capaces de fijarnos como prioridad el desarrollo de una cultura de la legalidad en el mediano y largo plazo, difícilmente podremos dejar atrás situaciones criminógenas y anémicas que arrastramos desde hace siglos; no escaparemos del séptimo círculo de infierno y tampoco será posible un crecimiento económico sostenido con derechos y 
libertades para todos. ${ }^{6}$ Pero precisamente, esta vigencia radica en la eficiencia del andamiaje jurídico, es decir mientras menos se evoque una norma, en un proceso integrador del respeto y el decoro.

El servicio de impartición de justicia tiene una cobertura deficiente a nivel local y nacional, lo que se agrava en localidades alejadas y en conflictos de menor cuantía. Las condiciones físicas y materiales son inadecuadas para proporcionarlo de forma eficaz y eficiente. La reticencia a la transparencia ha impedido el desarrollo de mecanismos homogéneos para supervisar y controlar la labor de los juzgados y los recursos que administran.

$\mathrm{Al}$ respecto, en nuestro país el mantra institucional parece que venía funcionando de forma aceptable, aun con la persistencia de una promoción del respeto a las normas jurídicas, entendidas como cultura de la legalidad. El cual es tema toral al considerar que las personas no están en la disposición y convencidas de respetar las leyes, el sistema de la legalidad seguirá reproduciéndose a magnitudes amplias, anulando cualquier avance que en materia de procuración de justicia se pueda aspirar. En términos de Arendt, podríamos decir que el juicio no es razón práctica, la razón práctica razona, y me dicta qué debo y que no debo hacer; establece la norma y es idéntica a la voluntad, y ésta expresa mandatos, hablemos de imperativos.

Bajo esa línea de acción los últimos años hablar de cultura de la legalidad se ha vuelto un lugar común en todos los ámbitos y todas las sociedades. Las reformas de los sistemas judiciales buscan el fortalecimiento judicial, mismas que son importantes, pero por el simple hecho de su existencia resultan insuficientes e inadecuadas. Ya que para que un sistema que funcione, son solo una parte de la aritmética normativa. La parte más importante constituye a la aplicación de la ley, misma que habría de moverse en coordinación con los esfuerzos por promover

\footnotetext{
${ }^{6}$ Sobre la cultura de la legalidad mayo 27, 2019 Escrito por: Miguel Ángel Antemate Mendoza http:// derechoenaccion.cide.edu/sobre-la-cultura-de-la-legalidad (Consultado el 29 de enero de 2020)
} 
la cultura de la legalidad y así impactar positivamente en amplios espectros que en la sociedad deben ser incluidos. La cultura de la legalidad presupone que aun cuando los gobiernos asuman el rol guía, la responsabilidad de proveer de un ambiente de legalidad para la ciudadanía y para todas las organizaciones civiles, religiosas, educativas, de negocios, entre otros (Rebolledo, 2014. p. 159).

En esa sintonía, me permito afirmar que en términos de materialismo histórico es la superestructura la que edifica o destruye la cultura de la legalidad. De tal suerte, que para que el cambio cultural se dé debe generarse una sinergia. La cultura de la legalidad existe cuando la cultura, ethos y pensamientos dominantes en una sociedad simpatizan y están en correspondencia con la observancia de la ley y cree que dicha ley debe ser aplicada sin distingo de felicitación política, posición social, religión o raza.

Paradójicamente este arquetipo de la presencia de la legalidad no significa que todos los individuos en esa sociedad creen en la viabilidad o conveniencia del Estado de Derecho, sino que el ciudadano común cree que las normas legales son parte fundamental de la justicia o que pueden y deben usarse para alcanzarla, y que los sistemas que emplean pueden aumentar la calidad de vida de los individuos en la sociedad.

Reflexionando sobre los ideales liberales en 1960, no mucho después de haber resistido su mayor prueba, el economista Friedrich Hayek observaba, "Para que las viejas verdades continúen dominando la mente de los hombres, han de reformularse en el lenguaje y los conceptos de las generaciones sucesivas" (Pinker, 2018. p.15).

Ignorar el alcance del progreso humano puede conducir a síntomas más graves que la angustia existencial. La razón es la certeza que nos brinda la existencia de la ley. La certeza jurídica, entonces, consiste simple y llanamente en conocer con anterioridad a la comisión de una acción determinada cuáles son las posibles sanciones a las que podemos hacernos acreedores (Salazar, 2008). 
Es decir, se busca la verdad, consecuencias jurídicas y equilibrios, la verdad jurídicamente objetiva, realidad. La verdad formal procesal vs verdad real. Lo que se quiere y lo qué hay, con la correspondencia del hecho y la realidad. Búsqueda de aproximaciones (certeza) verdad construida, podría decir, sin adelantarnos que el amparo abraza la causa de la verdad procesal, (la verdad llega al final) tesis y antítesis donde el método acusatorio es el más científico, pero quizás no el más socialmente conocido o aceptado por ser menos inquisitivo.

Vivir como vivimos, bajo un imperio de la ley incipiente, no significa que estemos atravesando por una situación de excepción, en el sentido de que tengamos un gobierno ilegal o inconstitucional. Significa que nuestra vida pública, el actuar cotidiano de funcionarios y ciudadanos, no refleja los ideales contenidos en el texto constitucional (Solís Gadea, 2018. p. 25)

Establecer el impero de la ley, o el Estado de derecho, es una tarea de largo aliento. Sin embargo, debemos emprenderla ahora, y defender los rubros alcanzados, con el apoyo de las instituciones del Estado y las organizaciones políticas y cívicas. Si los mexicanos no entendemos la importancia de esta labor, pospondremos para un triunfo inalcanzable el país, con el que hemos soñado desde que nos independizamos.

De esta manera, aún bajo el mandato del régimen más despiadado y absurdo, podemos decidir cuál será el curso de nuestro comportamiento. Esa posibilidad nos brinda un mínimo de seguridad que no tendríamos en un Estado en el que los gobernantes van decidiendo día a día y de manera caprichosa cuales son las acciones punibles y cuáles son las penas aplicables.

Uno de los exponentes con mayor influencia en la exposición de las normas es H-L. Hart (2007). Este autor está en desacuerdo con Kelsen, dado el enfoque represivo que le impone a su definición y porque no tomó en cuenta otro tipo de normas. Para Hart, las normas son primarias y secundarias. Las primarias son las que prescriben derechos y obligaciones. Hart descubre que Kelsen no tomó en consideración las normas secundarias. En estas últimas se encuentran tres tipos: las de reconocimiento, 
las de cambio y las de adjudicación. En gran medida, la teoría del derecho actual parece seguir estos parámetros, aunque con algunos ligeros ajustes

La vigencia de la norma jurídica es un elemento esencial cuya condición es que la norma jurídica que se deriva de las normas jurídicas básicas u originarias haya sido expedida conforme a criterios establecidos por éstas. En otras palabras, las normas básicas u originarias son el fundamento de validez de las normas creadas a partir de ellas. Este planteamiento nos permite establecer la diferencia entre dos conceptos jurídicos más, que son de gran trascendencia para nuestro estudio, como separación de vigencia y validez.

Hay vigencia cuando las normas jurídicas son observadas de manera generalizada por la sociedad, y hay validez cuando las normas han sido expedidas conforme a procedimientos previamente establecidos, características definitorias de las normas jurídicas, pues ellas solo pueden existir cuando tienen validez. Es decir, a diferencia de otras normas o reglas, se dice que las normas jurídicas reclaman su validez, ya que sin ésta no tienen exigencia. Así la cultura de la legalidad debe apostar esta lógica, y teniendo como sostén al elemento que oxigena la legalidad. Es así como, aunque sea de forma marginal, las leyes constituyen un límite a la actuación. Pero la certeza jurídica solo es posible cuando las leyes tienen dos características: generalidad y abstracción.

Las normas son generales cuando están dirigidas a clases abiertas a sujetos. Es decir, cuando no son privativas o singulares. La fórmula típica de una ley general sería la siguiente: "todos los individuos tienen los siguientes derechos y obligaciones...". La forma típica de una ley privativa sería, en cambio, la siguiente: "Fulano de tal tiene los siguientes privilegios...". Si las leyes están redactadas con fórmulas generales nos ofrecen la certeza de que todos los sujetos que forman parte de la categoría a las que están dirigidas son acreedores de las consecuencias que la propia ley contempla. 
Si las leyes son privativas, en cambio, sus supuestos sólo valen para unos pocos y dejan fuera a todos los demás. En ese grado la generalidad es un atributo de las leyes que contribuyen a brindar certeza jurídica, pero ofrece un piso de igualdad formal.

La idea de un sistema jurídico sostiene la autonomía del derecho con relación a otros sistemas sociales. Desde esta perspectiva, el sistema jurídico es una entidad autónoma con una estructura explícita compuesta esencialmente por tipos de elementos: normas jurídicas o instrumentos de para su aplicación. Las normas son aquellas disposiciones emanadas de un poder legítimo que, en diversos momentos, nos indican cómo actuar o qué conducta debemos adoptar, de tal suerte que una norma es válida significa que derivó de procedimientos de creación establecidos por la norma superior. No es que sea "valioso" lo que se reglamenta. A fin de sustentar la paridad particularidades, se motiva sobre derecho no sobre hechos. Veredicto es la unanimidad con respeto al sistema de pruebas. Pero si existe una baja cultura de la legalidad se construye el derecho Ordalías (orden divino) lo que nos lleva a una rueda de ineficiencia, donde ahora con los medios parecemos volver al modelo inquisitivo que es lo peor que nos puede pasar. Se prueban hechos capacidad para probar hechos, jamás probar opiniones, y la percepción son opiniones basadas en construcciones culturales. Sin embargo, la vida material se confecciona de lo que le suceden a las personas y a las instituciones.

\section{Relevancia del Juicio de Amparo}

El juicio de amparo es el medio de protección constitucional con características propias, que se hace valer a instancia de parte agraviada contra actos cometidos por autoridades de cualquier ámbito gubernamental, que se hayan traducido en la violación de las garantías individuales, con el fin de que una sentencia restituya al afectado en el pleno goce de la garantía vulnerada en su contra. El amparo se encuentra en el marco del llamado derecho procesal constitucional por los caracteres y los efectos de sus decisiones: en resumen, las reglas a través de las cuales la Constitución se pone en condición de desempeñar la función de criterio 
de juicio práctico para la resolución judicial de las controversias pertenecientes a su esfera (Gustavo Zagrebelsky, 2004)

Para el caso mexicano a nivel federal los juicios son 4: Amparo, Acción de Inconstitucionalidad y Controversia Constitucional. A nivel local se da la acción de inconstitucionalidad local. Juicio para la protección de los derechos políticoelectorales del ciudadano(JDC) y Juicio de Revisión Constitucional electoral(JRC) Otra característica para que se dé el Imperio de la Ley es que esta sea eficaz, legitimada, que sea cumplida por el gobernado, acatada la eficacia se debe encontrar en todo el sistema jurídico, en un cuerpo normativo o en una ley en especial, entonces cuando esta condición no se encuentra el amparo viene como calza a emparejar el debilitamiento de administración de justicia. El Dr. Héctor Fix-Zamudio (p.97) explica que el juicio de amparo constituye la garantía constitucional por antonomasia, no entendida en el concepto tradicional que le identifica con los hechos de la persona humana consagrados constitucionalmente, que está dirigido a la reintegración del orden jurídico constitucional cuando éste ha sido desconocido o violado por los propios órganos del poder.

Asimismo, señala que es la institución procesal más importante del ordenamiento mexicano, ya que protege prácticamente a todo el ordenamiento jurídico nacional con cinco instrumentos procesales:

- Instrumento protector de la libertad personal similar al hábeas corpus

- Único medio para impugnar las leyes inconstitucionales en casos concretos, recibiendo, entonces, el nombre de amparo contra leyes

- Medio de impugnación de último grado contra las resoluciones judiciales de todos los tribunales del país, tanto locales como federales, sector al que se denomina amparo de casación

- Instrumento para impugnar las resoluciones o actos de las autoridades cuando los mecanismos no pueden combatirse ante un tribunal administrativo, por lo que este sector funciona como un proceso de lo contencioso administrativo, y

\section{DERECHO GLOBAL. ESTUDIOS SOBRE DERECHO Y JUSTICIA}


- El amparo agrario Sobre este punto José Manuel de Alba de Alba (2015) dispone agregar otros tres instrumentos procesales

- Lo incorporado a la Ley de Amparo en la fracción VII, en la que el juicio de amparo se erigió también como un medio de defensa con el que cuenta el ofendido en contra del no ejercicio de la acción penal

- Instrumento que se promueve para que sujetos ajenos a una relación jurídica procesal preexistente no se vean afectados por ese juicio, por tener interés en el resultado de éste, al existir un derecho comprometido en él; con lo cual este sector hace las veces de tercería

- Instrumento por medio del cual se puede nulificar la cosa juzgada por no haber estado integrada debidamente la relación jurídica procesal, pudiendo ser, por un indebido emplazamiento o, por omitir llamar a un sujeto que debía ser parte del proceso, sector que se asemeja a un juicio de nulidad de proceso fraudulento

En México cuando una gobernada estima que una ley trasgrede los principios que contienen en la Constitución, tiene a su alcance el juicio de amparo para impugnar por esta vía la inconstitucionalidad de dicho ordenamiento, esta modalidad estuvo inspirada en la revisión judicial de inconstitucionalidad de leyes, derivada de la legislación de los Estados Unidos de América.

Se puede afirmar que el amparo contra leyes protege tanto la parte dogmática como la orgánica de la Constitución, entendiendo a la primera como la que contiene una serie de verdades que se reputan validas de suyo, conocidas como garantías individuales, visibles en los artículos 1 a 29, aunque también se encuentran dispersas en otros ordenamientos de la Constitución y la segunda, cómo aquella en la que se limita las competencias de los poderes estatales. En otras palabras, con el juicio de amparo se protege toda la constitución, excepción de las normas de carácter electoral.

Cuando el amparo protege al quejoso contra leyes violatorias de garantías individuales, se denomina amparo contra leyes. Si se promueve contra actos violatorios de garantías, se conoce como amparo-garantías. Si de interponer 
contra la inexacta y definitiva aplicación de la ley al caso concreto, se está en presencia de un amparo-casación o amparo-recurso. Por el último, si el amparo se intenta contra la existencia de invasiones reciprocas de la soberanía federal o de los Estados, se le conocerá como amparo soberanía o amparo por invasión de esferas (Fix- Zamudio y Héctor Fix-Fierro, 2003. p. 115)

Este juicio se rige por diversos principios:

A) Principio de la iniciativa o la instancia de parte. El amparo solo puede ser promovido por la parte agraviada por un pacto de autoridad que, en su concepto, ha conculcado sus garantías.

B) Principio de existencia de agravio personal y directo. El agravio es la provocación de un daño o perjuicio a una persona en relación con las garantías constitucionales que ella se atribuye.

C) Principio de definitividad. El juicio de amparo no puede promoverse si antes no se han agotado los juicios, recursos o medios de defensa que la ley rige el acto establezcan, y que tengan por objeto modificar o nulificar dicho acto.

D) Principio de tramitación jurisdiccional. El amparo es una institución que se tramita ante órgano jurisdiccional y adopta la forma de juicio.

E) Principio de estricto derecho y suplencia que la queja: El juzgador de amparo debe limitar su función jurisdiccional a resolver sobre los actos reclamados y conceptos de violación expresados en la demanda, sin hacer consideraciones de inconstitucional o legalidad que no haya hecho valer el quejoso. El principio de estricto derecho admite como excepción la suplencia de la queja, que consiste en corregir los errores en las demandas de amparo en las materias agrarias, penal y laboral, sobre todo.

F) Principio de relatividad. La resolución solo beneficia o perjudica a quien promovió el juicio de amparo ("fórmula Otero"), no al resto de los gobernados; es decir, la sentencia de amparo no tiene efectos erga omnes. 
Muestra palmaria de que en el país la utilización del amparo es elemento esencial para el sostenimiento de la actividad jurídica, y esto no es solo una percepción lo podemos reforzar con lo reportado en el CENSO NACIONAL DE IMPARTICIÓN DE JUSTICIA FEDERAL 2016 y 2019. Del total de asuntos que tuvieron conocimiento los órganos jurisdiccionales de la Suprema Corte de Justicia de la Nación (SCJN) durante el año 2016, destacan los procedimientos de “Amparo Directo en Revisión", que representaron el 44.7\% y 50.6\% de ingresos y resoluciones, respectivamente. La distribución de los asuntos por tipo de procedimiento para el año 2016 se presenta en la siguiente gráfica:

Gráfica 1. Distribución porcentual de los asuntos ingresados y resueltos por los órganos jurisdiccionales de la SCJN, según tipo de procedimiento para 2016.

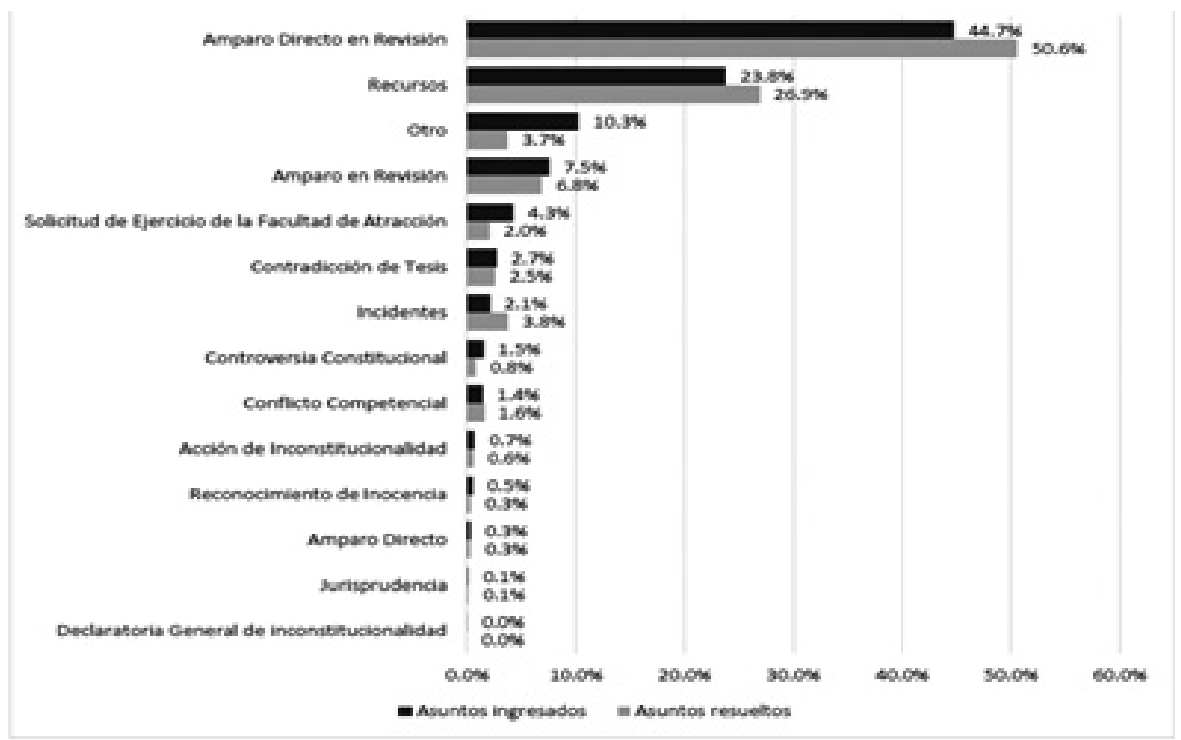

Fuente: Censo Nacional de Impartición de Justicia Federal 2016 
Del “Amparo Directo en Revisión”, que significó el tipo de procedimiento con mayor frecuencia estadística, el porcentaje de resolución ${ }^{1}$, desde el año 2010 al 2016, se aprecia en la siguiente gráfica:

Gráfica 2. Porcentaje de resolución de asuntos del procedimiento Amparo Directo en Revisión (SCJN)

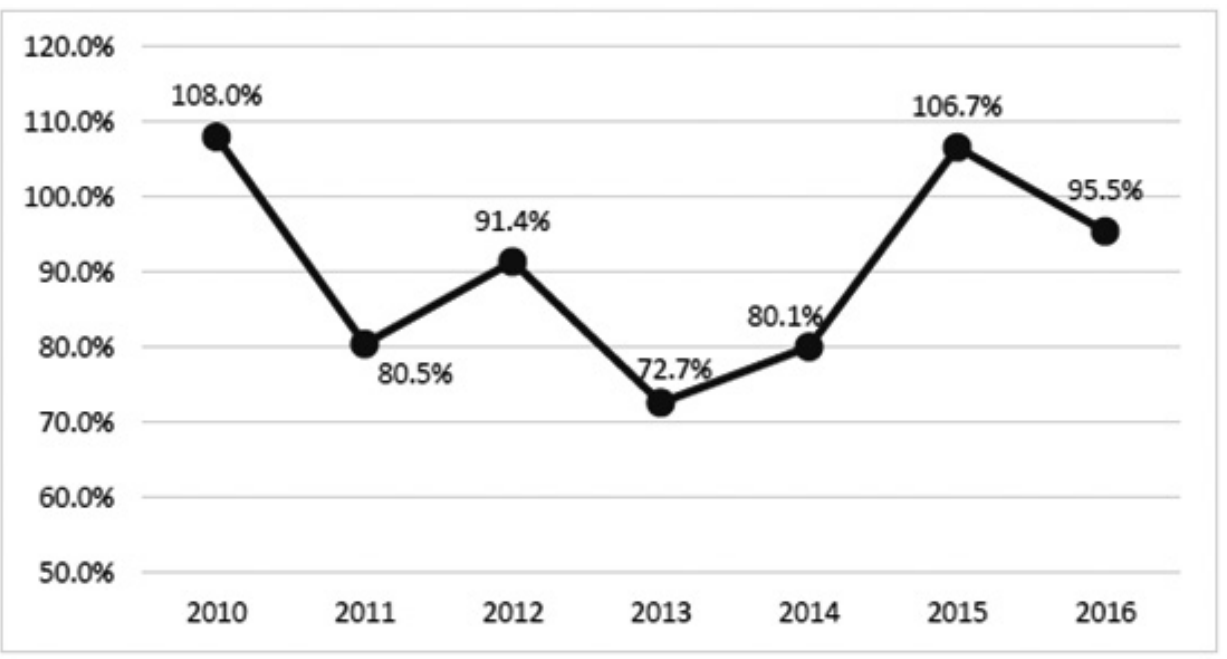

Fuente: Censo Nacional de Impartición de Justicia Federal 2016

Asimismo, del procedimiento "Acción de Inconstitucionalidad", que representa uno de los procedimientos sustantivos más importantes de la SCJN, el porcentaje de resolución en dicho periodo se presenta en la Gráfica 3:

Gráfica 3. Porcentaje de resolución de asuntos del procedimiento Acción de Inconstitucionalidad (SCJN)

\footnotetext{
${ }^{1}$ El porcentaje de resolución se obtiene de la división de los asuntos resueltos entre la totalidad de los asuntos ingresados durante el año de referencia.
} 


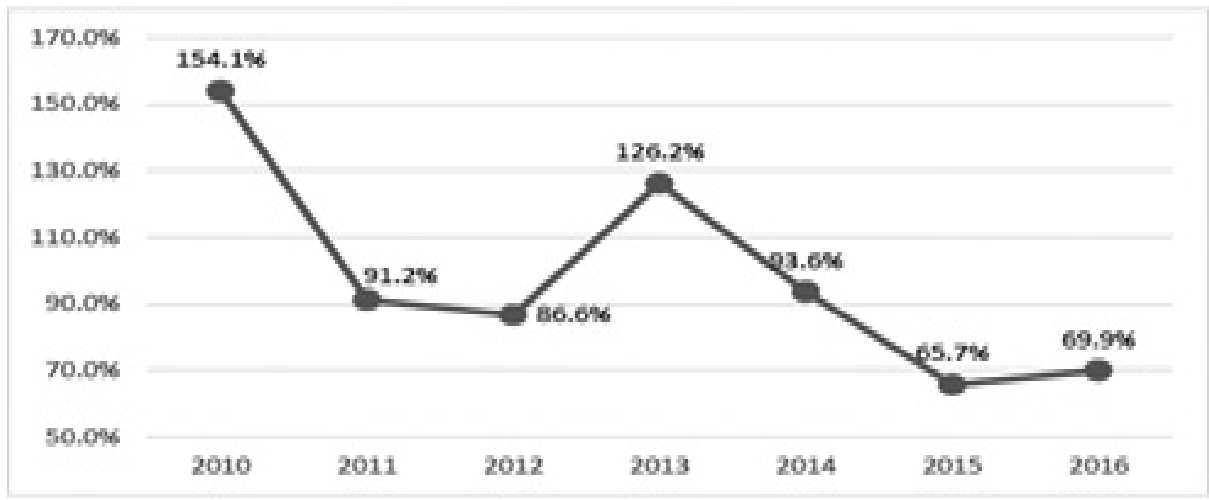

Fuente: Censo Nacional de Impartición de Justicia Federal 2016

Por su parte, los datos sobre el ejercicio de la función de los órganos jurisdiccionales del TEPJF muestran que durante el año 2016 ingresaron un total de 10 mil 134 asuntos, por 10 mil 826 asuntos resueltos.

En 2018 el procedimiento de "Amparo Directo en Revisión representó la mayor proporción de los asuntos ingresados a los órganos jurisdiccionales de la SCJN 49.8\% mientras que su proporción en asuntos resueltos fue del $50.5 \% \mathrm{La}$ distribución por tipo de procedimiento se presenta a continuación:

Gráfica 4. Distribución porcentual de los asuntos ingresados y resueltos por los órganos jurisdiccionales de la $\mathrm{SCJN}$, según tipo de procedimiento para 2018 


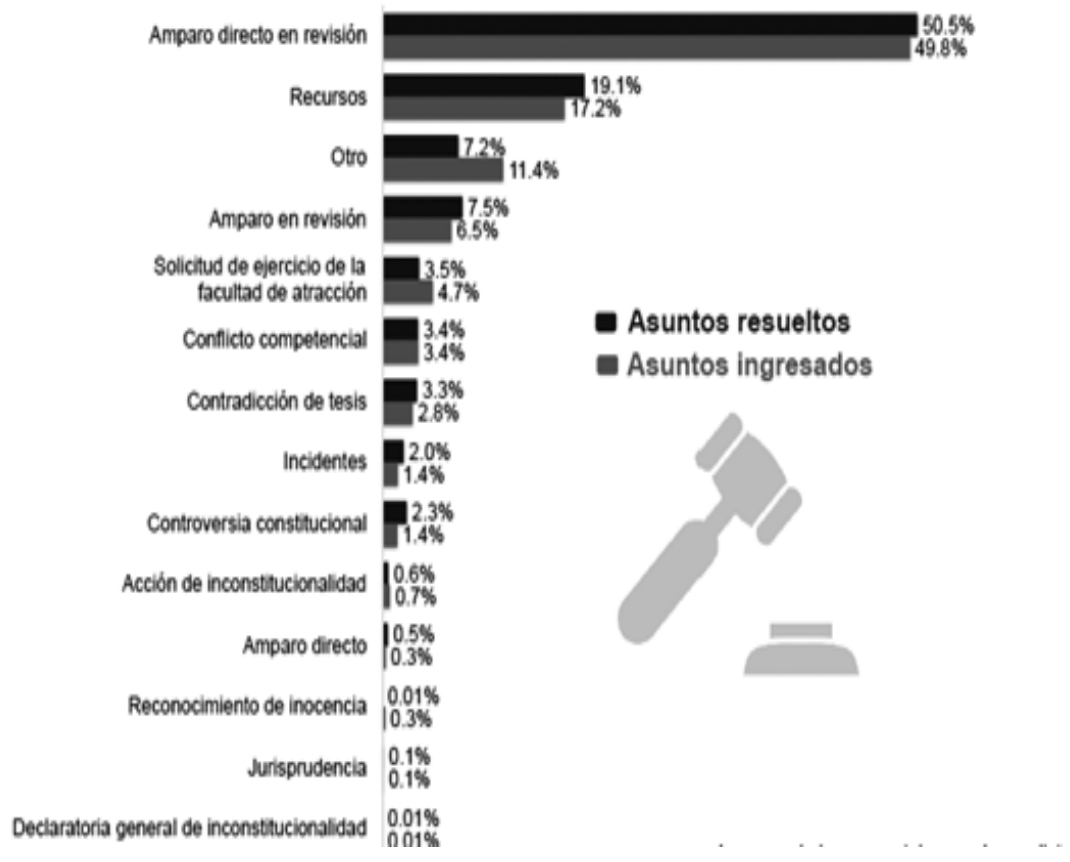

Fuente: Censo Nacional de Impartición de Justicia Federal 2019

Del Amparo Directo en Revisión que significó el tipo de procedimiento con mayor frecuencia estadística, y la Acción de Inconstitucionalidad que representa uno de los procedimientos sustantivos más importantes de la SCJN, el porcentaje de resolución ${ }^{7}$ en estos dos tipos, desde el año 2010 al 2018 se aprecia en las siguientes gráficas:

\footnotetext{
${ }^{7}$ El porcentaje de resolución se obtuvo de la división de los asuntos resueltos entre los asuntos ingresados durante el año. Las cifras pueden ser mayores al 100 por ciento, debido que se resolvieron asuntos ingresados en años anteriores.
} 


\section{Gráfica 5}

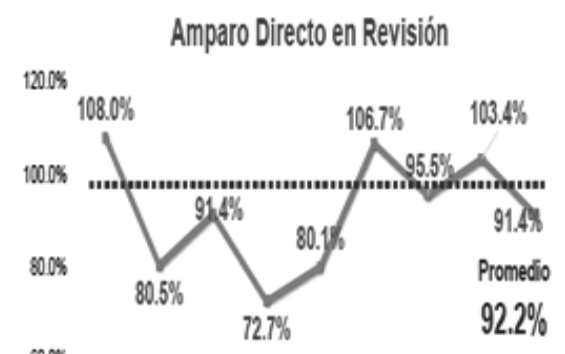

$600 \%$

$400 \%$

$200 \%$

005
Gráfica 6

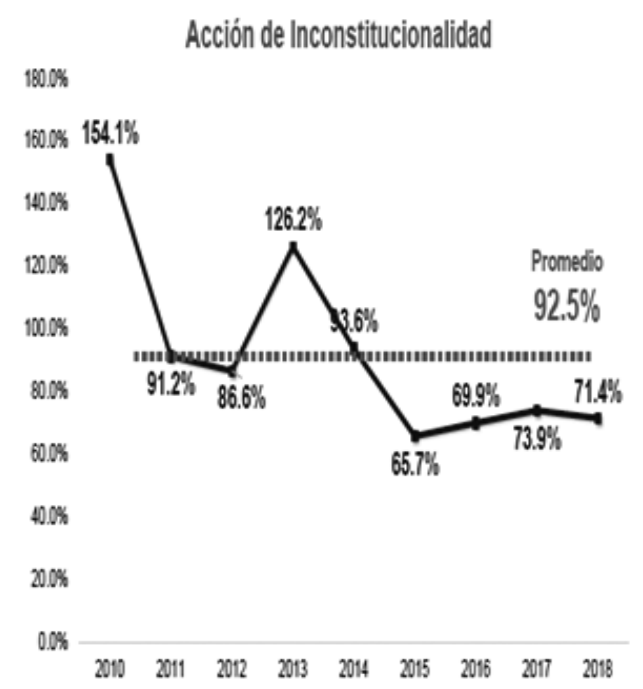

Fuente: Censo Nacional de Impartición de Justicia Federal 2019

Para el Amparo Directo en Revisión el principal tipo de resolución fue Desechamiento $68.2 \%$ mientras que para Acción de Inconstitucionalidad como Recursos fue "Sentencia de Fondo" (62.4\% y $84.4 \%$ respectivamente) 
Gráfica 7

Amparo Directo en

Revisión



\section{Grafica 8}

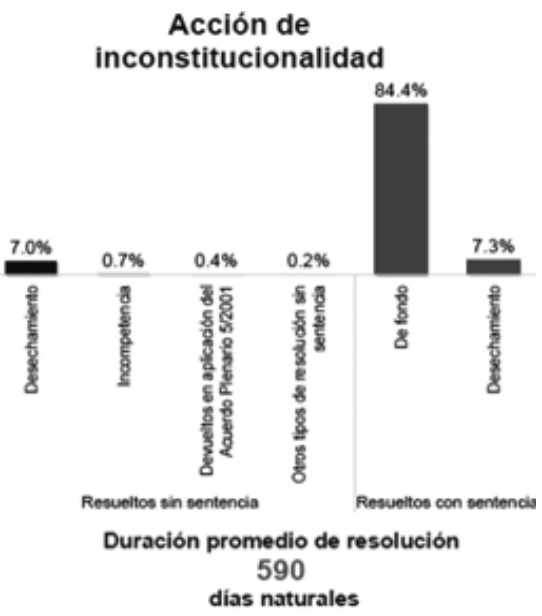

Fuente: Censo Nacional de Impartición de Justicia Federal 2019

En 2018 el procedimiento de "Amparo Directo" representó la mayor proporción de los asuntos tanto ingresados como resueltos en los Tribunales Colegiados de Circuito (47.5\%). El porcentaje de resolución en estos tres procedimientos (amparo directo, en revisión y queja), desde el año 2010 al 2018 como podemos observar en las siguientes gráficas: 
El Juicio de amparo como piedra de toque de la Cultura de la Legalidad
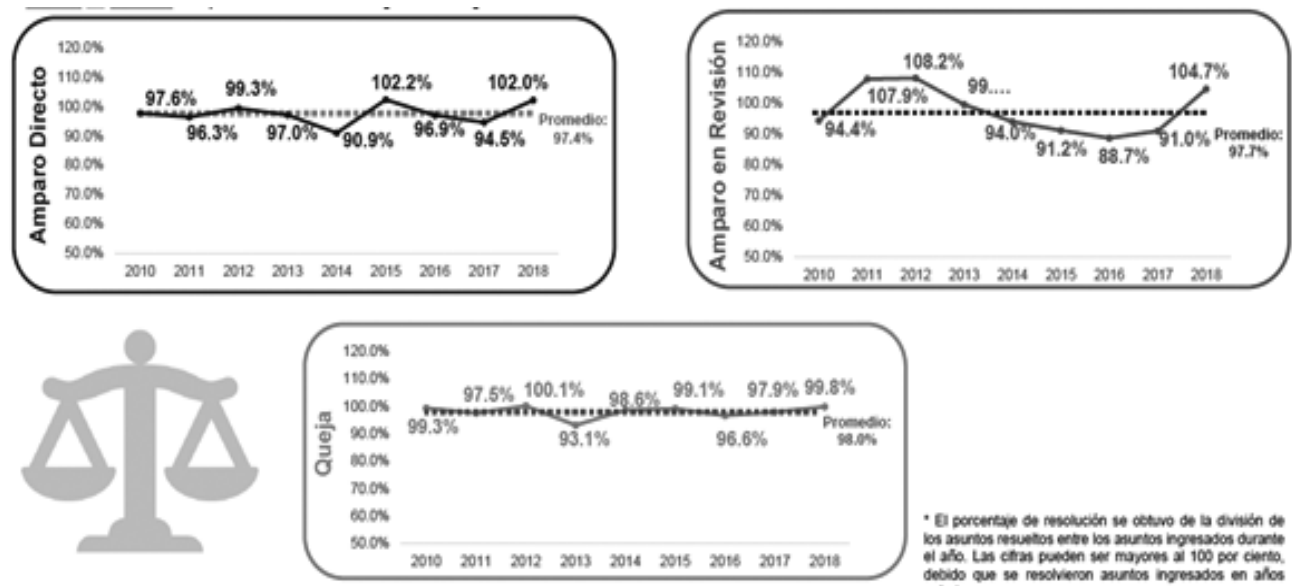

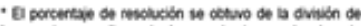
los asurtos resuetios entre los murtos ingresados durrite debids que se rescliveron asurtos ingresados en alos anteriores.

Fuente: Censo Nacional de Impartición de Justicia Federal 2019

Para el Amparo Directo el principal tipo de resolución fue No Amparar 46.9\%, en cuanto a Amparo en Revisión, la mayor cantidad de asuntos fueron resueltos con Sentencia Confirmatoria 56.4\% y la mayor cantidad de quejas se resolvieron como infundadas $41.6 \%$

En 2018 el procedimiento de "Amparo Indirecto" representó la mayor proporción de los asuntos ingresados a los Juzgados de Distrito 91.0\% así como de los asuntos resueltos que fue del 90.65\%. Para el Amparo Indirecto el principal tipo de resolución fue Sobreseimiento 37:6\%, y para Procesos Administrativos y Civiles fue Desechamiento 41:3\%

En definitiva, como se ha expuesto, los diversos reportes sobre administración de justicia muestran al Juicio de Amparo en sus diversas expresiones, y de conformidad con los reportes estadístico es el instrumento al que más se recurre para mantener la constitucionalidad, es decir los otros medios alternativos para resolver el procedimiento se ven rebasados, toda vez que en muchas ocasiones se brincan los tiempos por la baja certeza procesal y probatoria existente. Ya 
que el binomio certeza-coherencia va más allá de toda realidad y queda en la cosmovisión del grueso de la población y más del abogado defensor, que busca vacunarse ante una anomalía para los justiciables ante cualquier acto de autoridad, que podría estimarse violatorio de sus derechos humanos y garantías tuteladas por la constitución y los tratados internacionales.

Correspondencia-coherencia con respecto a la afectación de la esfera jurídica del gobernado en virtud de su especial situación frente al orden jurídico. Ya que por incapacidad de quienes administran justicia, o por intereses políticos la autoridad responsable desempeña un papel fundamental, siendo aquella que dicta, ordena, ejecuta o trata de ejecutar $u$ omite dictar al acto que crea, modifica o extingue situaciones jurídicas en forma unilateral y obligatoria, donde cuenta con la postura inexcusable de que el derecho es -y no lo que el momento político marcael factor fundamental de la justicia. De lo contrario se deslegitima el accionar, ya que la moral del derecho se sustenta en la legitimidad popular y no en la cultura del amor al objetivo de correspondencia procesal, pero si al amor a la coherencia.

Centrando nuestra legitimidad y la cultura de la legalidad en máximas de la experiencia, buscando cada vez más los arreglos extrajudiciales. Y no las reglas de la lógica. No hay convicción, solo dudas razonables. Alejándonos de las pruebas directas y sustentando la mayor parte de los hechos jurídicos en visiones subjetivas. Manos en la masa o masa en las manos.

La cultura de la legalidad en México parece más convencer con el corazón y no con la razón, socialmente hace falta que te crean que lo motive razones, más allá de las pruebas como fuente de información, es decir, testigos, peritos, documentos y objetos. Ya que se presume que de entrada los indicios atienden a sectores privilegiados, por tanto, el amparo por violación al procedimiento ya es un perjuicio. Casi todo se puede verificar, lo que se hace deja huella. La convicción por la prueba puede mejorar la cultura de la legalidad.

\section{DERECHO GLOBAL. ESTUDIOS SOBRE DERECHO Y JUSTICIA}




\section{Conclusiones}

Como hemos reflexionado en el presente ensayo, la Cultura de la Legalidad es un pensamiento compartido sobre la responsabilidad individual de apoyar, fortalecer y actuar de acuerdo con el Estado de Derecho a partir de ello, hemos entendido la cultura como un conjunto de actitudes compartidas, valores, convenciones, creencias y prácticas que gobiernan una sociedad bajo cierta estructura social, a fin de que exitista una cultura de legalidad, misma que permea cuando la mayoría de las personas apoyan activamente el Estado de Derecho o cumplimiento general de las normas abstractas y/o precisas, basado en una convivencia democrática donde se garanticen sus derechos.

Para ello es necesaria la obediencia y simpatía por la norma, teniendo como punto relevante la configuración de una de las mayores preocupaciones y desafíos estatales. La cultura de la legalidad tiene como su mayor significación vincular el derecho con el tejido social y con la vida orgánica de quienes administran los poderes de la unión (ya en un marco constitucional), con la finalidad de lograr una sociedad cabalmente humana.

En México se ha encontrado demasiados obstáculos para hacer de la justicia algo tangible. Esto nos llevó a indagar sobre las causas generales en las deficiencias que se desprenden de la organización y funcionamiento de los poderes judiciales, el amparo es el último Totem de protección, en virtud de la defensa del derecho subjetivo privilegiado por la ley, el cual pudiera resultar afectado por la sentencia dictada, derivado de que el amparo es un medio de control de constitucionalidad y de la convencionalidad, con el que cuenta cualquier persona para defenderse de la violación de sus derechos humanos cuando las ve restringidas o destruidas por un acto de autoridad y procedencia.

Preciso es, que la Cultura de la legalidad acuda en su ejercicio procesal siempre hacia la prueba y no a la inquisición, ya que la perturbación del llamado populismo 
jurídico a través de los medios de comunicación, en lugar de informar obstaculizan el acceso a la justicia, generando impunidad. Esto continuaría provocando que el amparo sea la piedra de toque de la comunidad, toda vez que se presentan profundos espacios de incertidumbre respecto a los resultados de un juicio, ante ello el amparo surge como un altar para dar certeza a los Derechos Humanos. 


\section{Bibliografía}

, (2001): El derecho de gentes (Madrid: Editorial Paidós). (Castro, Juventino, V., Garantías y Amparo).

Índice Global de Impunidad, elaborado por la de la Universidad de las Américas Puebla (UDLAP) y Consejo Ciudadano de Seguridad y Justicia de Puebla (CCSJ).

Rodolfo, Vázquez. (S.F). Teoría del derecho, p.55.

"Los Mexicanos y su Constitución. Tercera Encuesta Nacional de Cultura

Constitucional. Centenario de la Constitución de 1917., Universidad

Nacional Autónoma de México, Instituto de Investigaciones

Jurídicas. Coordinadores: Héctor Fix Fierro, Julia Isabel Flores, Diego Valadés, Páginas 32 a 44, Año 2017.

Censo Nacional de impartición de justicia federal 2016 y 2019.

Correa Ortiz, J. (2016). "Cultura de la Legalidad y Derechos Humanos",

Comisión Nacional de los Derechos Humanos.

Cossío Díaz, José Ramón. (2018). El sistema de justicia. México: FCE.

Fix- Zamudio, Héctor y Héctor Fix-Fierro. (2003). "Amparo "en VV.AA.,

Nuevo diccionario jurídico mexicano, México.

Fix-Zamudio, Héctor. (2005). "Estudio de la Defensa de la constitución en el ordenamiento mexicano", México, Porrúa.

García de la Cruz Herrero, Juan José. (2006). "Diccionario de sociología", Giner, Lamo y Torres (eds), Alianza Editorial, Madrid.

García Máynez, Eduardo. (1960). "La definición del derecho", Universidad Veracruzana, Xalapa, México, p.25.

Hayek, Friedrich A. (2015). "Camino de servidumbre" / —Colec. ALIANZA)

Hart, Jonh Ely. (2007). "Democracia y Desconfianza. Una teoría del control constitucional”. España. Editorial Siglo del Hombre.

Hernández Abascal, A. (2006), "¿Qué es la justicia de la Constitucionalidad?”, México, Editorial Códice. 
http://derechoenaccion.cide.edu/sobre-la-cultura-de-la-legalidad

(Consultado el 29 de enero de 2020)

http://www.internet2.scjn.gob.mx/red/constitucion (Consultado el día 28

de enero de 2020)

Índice de Estado de derecho (2019) World Justice Project (WJP)

de Alba de Alba José Manuel (2015). "La apariencia del buen derecho en serio" Editorial Porrúa)

Kant, Immanuel. (2019). "Lo bello y lo sublime”. España. Green BooksEditorie.

Locke, John. (1999). "Ensayo sobre el entendimiento humano"/John Locke; trad. de Edmundo O'Gorman-2 ed. México: FCE. Locke, John. "Carta sobre la tolerancia" / - (Colec. TECNOS)

Malem, Seña. (1999).”La corrupción aspectos éticos, económicos, políticos y jurídicos" (Madrid: Editorial Gedisa)

Márquez, Rábado. (S.F). "El Estado de derecho en México". Instituto de Investigaciones jurídicas de la UNAM, México.

Patricia, Fuentes. (2014). "Las ideas políticas en América Latina". México: EL Colegio de México.

Pereznieto Castro, Leonel. (2017). "Introducción al estudio del derecho". Editorial Oxford.

Rawls, John. (1995). "Teoría de la justicia”, trad. de María Dolores González-2a ed. México: FCE.

Rawls, John. (1998). "Consideraciones sobre el significado del pecado y la fé"-(Colec. PAIDOS)

Rawls, John. (1999). "Justicia como equidad". Madrid: Tecnos.

Salazar, Pedro. (2008). "La educación y la legalidad”. México. Ediciones cal y arena.

Sartori Giovanni. (2003). “QQué es la democracia?”. México. Taurus.

SCJN (2012) "Elementos de Derecho Procesal Constitucional" Editorial SCJN, México. 
Smith, Adam. (2004). "Teoría de los sentimientos morales"; selec. e introd. de Eduardo Nicol ; trad. de Edmundo O'Gorman-3 $3^{\mathrm{a}}$ ed. México: FCE.

Solís Gadea en Aguilar Camín H. (2018). “YY ahora qué? México ante el 2018" Ilegalidad, Pag-47-56, Debate, México.

Steven Pinker. (2018)." En defensa de la Ilustración". México: Paidós. Suprema Corte de Justicia de la Nación. Las Garantías Individuales, Parte General, col Garantías Individuales, México, SCJN, 2003, p.46 Weber, Max. (2014). Economía y sociedad/Max Weber; ed. revisada y anotada por Francisco Gil Villegas; nota preliminar y trad de José Medina Echavarría; trad. de Juan Roura Parella, Eugenio Ímaz, Eduardo García Maynez, José Ferrater Mora, Francisco Gil Villegas - $3^{\mathrm{a}}$ ed. - - México: FCE.

Weber, Max. (2011). La ética protestante y el espíritu del capitalismo/ Max Weber ; introd. y ed. crítica de Francisco Gil Villegas; trad. de Luis Legaz Lacambra y Francisco Gil Villegas $-2^{\mathrm{a}}$ ed. México: FCE.

Zagrebelsky, Gustavo. (2004). “¿Derecho Procesal Constitucional? Y otros ensayos de justicia constitucional", México, Fundación Universitaria de Derecho, Administración y Política. 
